\title{
Robotic repair of vesicovaginal fistulae with the transperitoneal-transvaginal approach: A case series
}

\author{
Luciano A. Nunez Bragayrac ${ }^{1}$, Raed A. Azhar², Golena Fernandez¹, Marino Cabrera ${ }^{1}$, Eric Saenz¹, Victor \\ Machuca ${ }^{1}$, Robert de Andrade ${ }^{1}$, Oswaldo Carmona ${ }^{1}$, Rene Sotelo ${ }^{1}$ \\ ${ }^{1}$ Robotic and Minimally Invasive Surgery Center, Instituto Médico La Floresta Caracas - Venezuela, \\ ${ }^{2}$ University of Southern California Institute of Urology, Keck School of Medicine, University of Southern \\ California, Los Angeles, California, USA
}

\section{ABSTRACT}

Objective: To describe a novel technique of repairing the VVF using the transperitoneal-transvaginal approach.

Materials and Methods: From June 2011 to October 2013, four patients with symptoms of urine leakage in the vagina underwent robotic repair of VVF with the transperitoneal-transvaginal approach. Cystoscopy revealed the fistula opening on the bladder. A ureteral stent was placed through the fistulous tract. After trocar placement, the omental flap was prepared and mobilized robotically. The vagina was identified and incised. The fistulous tract was excised. Cystorrhaphy was performed in two layers in an interrupted fashion. The vaginal opening was closed with running stitches. The omentum was interposed and anchored between the bladder and vagina. Finally, the ureteral catheters were removed in case they have been placed, and an $18 \mathrm{Fr}$ urethral catheter was removed on the 14 th postoperative day.

Results: The mean age was 46 years (range: 41 to 52 years). The mean fistula diameter was $1.5 \mathrm{~cm}$ (range 0.3 to $2 \mathrm{~cm}$ ). The mean operative time was $117.5 \mathrm{~min}$ (range: 100 to $150 \mathrm{~min}$ ). The estimated blood loss was $100 \mathrm{~mL}$ (range: 50 to $150 \mathrm{~mL}$ ). The mean hospital stay was 1.75 days (range: 1 to 3 days). The mean Foley catheter duration was 15.75 days (range: 10 to 25 days). There was no evidence of recurrence in any of the cases. Conclusions: The robot-assisted laparoscopic transperitoneal transvaginal approach for VVF is a feasible procedure when the fistula tract is identified by first intentionally opening the vagina, thereby minimizing the bladder incision and with low morbidity.

\section{ARTICLE INFO}

Key words:

vesicovaginal fistulae;

robot-assisted laparoscopic

transperitoneal transvaginal

approach

Int Braz J Urol. 2014; 40: 810-5

Submitted for publication:

November 18, 2013

Accepted after revision:

May 03, 2014

\section{INTRODUCTION}

Vesicovaginal fistulae (VVF) represent a significant morbidity in female urology; the incidence varies between $0.3 \%$ and $2 \%$, most of them iatrogenic, other etiologies mentioned in the literature include pelvic trauma, radiation necrosis, illegal abortion, as well as radical pelvic surgery $(1,2)$. In developing countries, the main causes are obstructed labor due to poor obstetric care; meanwhile, in countries with adequate obstetric care, 90\% of VVF cases are caused by gynecological procedures. Hysterectomy, both with the transabdominal and transvaginal approaches, is the most common procedure that results in fistulae, and this procedure is the cause of $75 \%$ of fistulae $(2,3)$.

There is currently some controversy concerning the timing of the surgery and the type of procedure that should be used to repair fistulae. 
The decision between transvaginal and transabdominal approaches depends on the location of the fistula, its relationship with the ureteric orifice and the time between fistula formation and repair (3). The advantages of early vs. delayed repair are still debatable (4). The effectiveness of surgical correction of large fistulae has been described as ranging from $75 \%$ to $97 \%(3,5,6)$.

Nezhat et al. initially reported the first retrovesical laparoscopic VVF repair in 1994 (7). The largest laparoscopic series was reported by Sotelo et al. (8) using a transvesical approach that localizes the fistula tract without requiring additional vaginal incisions or further dissection of the vesicovaginal space. Once the fistula is identified, the vesicovaginal space is dissected to separate the structures; the importance of this technique lies in the intentional cystotomy for localizing the tract. The laparoscopic approach is primarily associated with similar success rates, minimal surgical trauma and reduced morbidity, allowing for more rapid convalescence $(4,8,10-16)$. Despite initial enthusiasm, laparoscopy has not gained popularity, most likely because laparoscopic VVF dissection and intracorporeal suturing are technically challenging. Robotic assistance in complex laparoscopic procedures has overcome the technical difficulties of the laparoscopic approach, even in challenging cases of recurrent VVF (17). Only a few reports of robotic vesicovaginal fistula repair have been described in the literature. Melamud et al. (18) in 2005 were the first to report this approach.

In this study, we present a novel technique, the robotic transperitoneal-transvaginal approach, which involves opening the vagina in order to identify the fistula tract.

\section{MATERIAL AND METHODS}

From June 2011 to October 2013, four patients underwent robotic repair of vesicovaginal fistulae with the transperitoneal-transvaginal approach.

All patients had symptoms of urine leakage from the vagina after abdominal hysterectomy. The first and fourth cases did not have any repair intention before this procedure; the second patient had a prior laparoscopic VVF repair and endosco- pic fulguration failure; and the third patient had a failure of robotic VVF repair with synthetic surgical glue that was extruded through the bladder and vagina. In all cases, we identified the fistula orifice with flexible cystoscopy as supratrigonal and/or near the ureteral orifice prior to surgery, which is a reason to not favor the vaginal approach. All patients were informed about the procedure and modification of the technique, an informed consent was signed for all the patients as a rule.

\section{Surgical technique}

Robotic repair of the vesicovaginal fistulae with the transperitoneal-transvaginal approach was performed under general anesthesia by an experienced surgeon. The patient was placed in low lithotomy position, a cystoscopy was performed to confirm the fistula orifice, and a stent was inserted through the fistula tract from bladder to the vagina. Ureteral stents were placed (cases No 3 and No 4) due to the proximity of the fistula opening to the ureteral orifice. A vaginal tamponade was inserted into the vagina up to the vaginal apex, which helped in vaginal stump identification and prevention of loss of pneumoperitoneum.

Access was gained at the umbilicus with cosmetic consideration by the Hasson technique. A $12 \mathrm{~mm}$ port was inserted with $30^{\circ}$ down lens, offering improved angles visulization and high definition optics that are useful when doing the anterior colpotomy; a $0^{\circ}$ lens could be used instead. Two $8 \mathrm{~mm}$ robotic ports were placed symmetrically on the left and right pararectal lines. We did not use a fourth arm, with the intention of minimizing scars, but a fourth arm could be used, and an 8 $\mathrm{mm}$ robotic port could be placed superior to the iliac crest on the left side. A $5 \mathrm{~mm}$ port was placed superior to the iliac crest on the right side, between the lens and the $8 \mathrm{~mm}$ port, for insertion of suction irrigation assistance. The robot was docked.

All patients had adhesions; therefore adhesiolysis was performed, using a combination of sharp and blunt dissection with Maryland fenestrated bipolar forceps and monopolar curved scissors, to expose the vaginal stump and the superior aspect of the bladder. An omental flap was prepared using the open omentoplasty technique 
(19), and the flap was brought down to ensure that it reaches the appropriate location between the bladder and the vagina. A stay suture was placed in the bladder using a straight needle and then exteriorized to maintain counter-traction. The needle was delivered into the abdominal cavity though the $12 \mathrm{~mm}$ trocar or inserted percutaneously. This counter-traction of the bladder could otherwise be performed by the robotic fourth arm. The vagina was identified with digital guidance allowing for safe insertion of the vaginal tamponade. Later the vagina was incised in a longitudinal direction according to the stent inside the fistula tract, 2 to $3 \mathrm{~cm}$ at level of the vaginal stump. The fistula tract was widely excised until viable fresh tissue was exposed (Figure-1). The $30^{\circ}$ up lens allowed for comfortable tract dissection. The bladder and vagina were dissected and separated. The vaginal opening was closed with care, maintaining an overlapping suture lines using running stitches in a horizontal fashion with absorbable braided suture. Cystorrhaphy was performed in two overlapping layers in a vertical fashion with absorbable braided suture. A bladder integrity test with methylene blue was performed. Omental flap was interposed and anchored between the bladder and the vagina (Figures 2 and 3). Finally, an optional flexible cystoscopy was performed to identify the ureteral orifices; the ureteral catheters were removed and an 18 Fr urethral catheter was removed on the $14^{\text {th }}$ postoperative day.

Figure 1 - Excision of the fistula tract. Notice the size of the fistula and the ureteral stent inside the bladder.

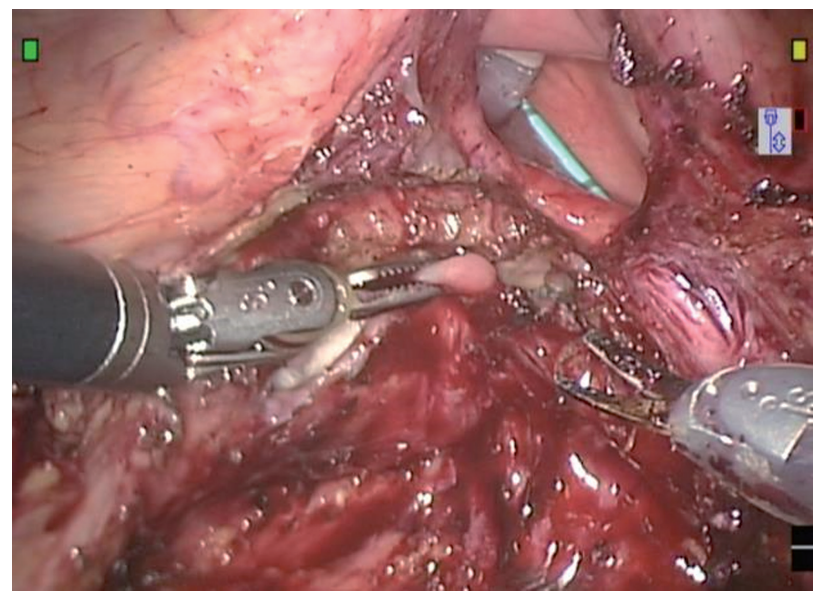

Figure 2 - Closure of the vaginal opening in a horizontal fashion with a braided suture.

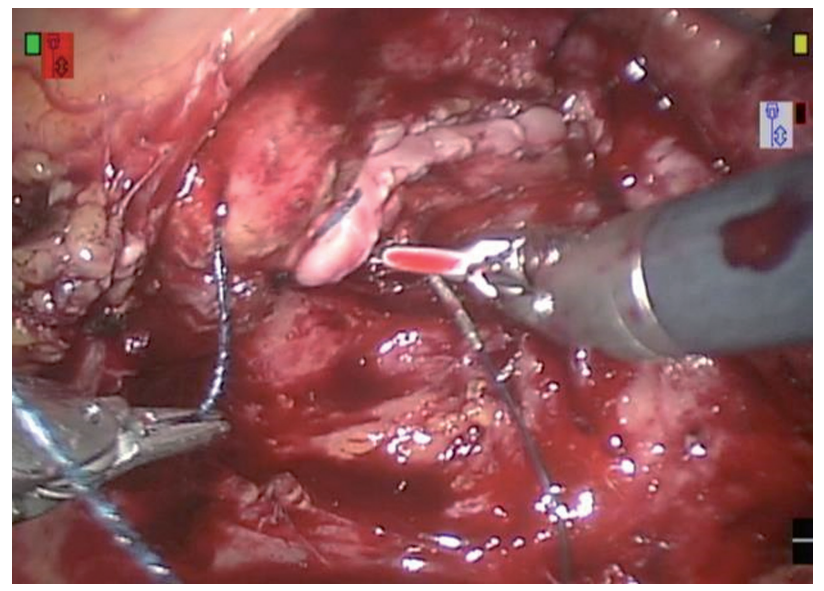

Figure 3 - Cystorrhaphy with a braided suture in a vertical fashion. Notice a suture above the bladder opening that was exteriorized to maintain counter-traction.

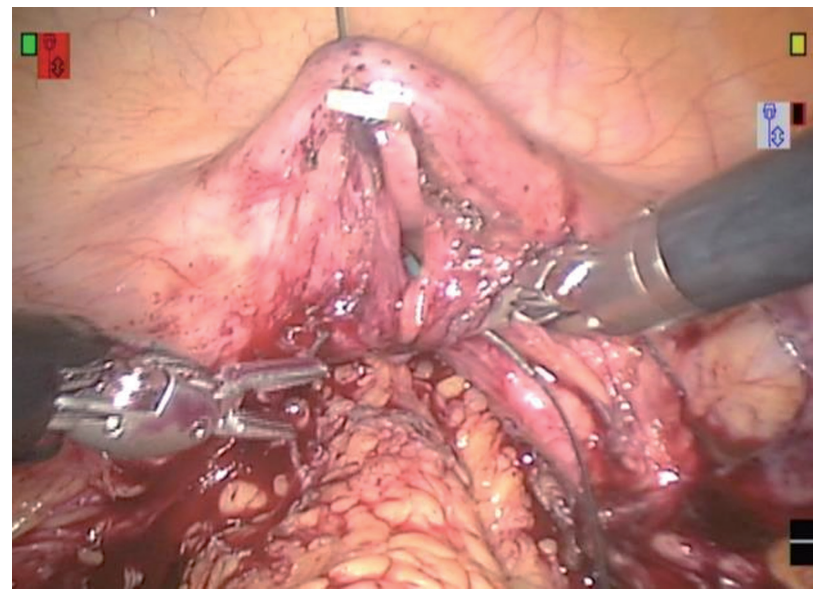

RESULTS

Of the 4 patients, with a mean age of 46 years (range: 41 to 52 years), 3 patients (75\%) had a complex VVF. All the patients had a prior hysterectomy. The mean fistula diameter was $1.5 \mathrm{~cm}$ (range: 0.3 to $2 \mathrm{~cm}$ ). The mean operation time was $117.5 \mathrm{~min}$ (range: 100 to $150 \mathrm{~min}$ ). The mean console time was $77.5 \mathrm{~min}$ (range: 60 to $100 \mathrm{~min}$ ). The mean estimated blood loss was $100 \mathrm{~mL}$ (range: 50 to $150 \mathrm{~mL}$ ). The mean hospital stay was 1.75 days (range: 1 to 3 days). Two patients (50\%) required ureteral stent placement with removal at the third 
day because of the proximity between the fistula opening and the ureteral orifice. The mean drainage time was 4.25 days (range: 0 to 10 days). The mean Foley catheter duration was 15.75 days (range: 10 to 25 days). The third patient had a delay in urethral catheter removal of 25 days due to previous failure of VVF repair and patient anxiety. In all patients, the omentum was used as interposed material. With a mean follow-up time of 14.25 months (range: 1 to 21 months), none of the patients had any evidence of recurrence (Table-1). orifices and especially in patients with multiple complicated or recurrent VVFs after transvaginal repair (17). Nevertheless, the approach chosen should be that with which the surgeon is most comfortable $(5,6)$

Laparoscopic VVF repair by different approaches has been described. Nezhat et al. (7) were the first to report the laparoscopic retrovesical approach in 1994, which decreases the morbidity of the abdominal approach with similar success rates that range from $86 \%$ to $100 \%$ and minimal

Table 1 - Evidence of recurrence.

\begin{tabular}{|c|c|c|c|c|c|c|c|c|c|c|c|c|c|}
\hline Age & $\begin{array}{l}\text { Type of } \\
\text { WF }\end{array}$ & $\begin{array}{c}\text { Fistula } \\
\text { diameter } \\
\text { (cm) }\end{array}$ & $\begin{array}{l}\text { Operative } \\
\text { time } \\
\text { (min) }\end{array}$ & $\begin{array}{l}\text { Console } \\
\text { time } \\
\text { (min) }\end{array}$ & $\begin{array}{l}\text { Estimated } \\
\text { blood loss } \\
\text { (mL) }\end{array}$ & $\begin{array}{c}\text { Interposed } \\
\text { material }\end{array}$ & $\begin{array}{l}\text { Hospital } \\
\text { stay } \\
\text { (days) }\end{array}$ & $\begin{array}{c}\text { Ureteral } \\
\text { catheterization } \\
\text { (days) }\end{array}$ & $\begin{array}{l}\text { Ureteral } \\
\text { stent time } \\
\text { (days) }\end{array}$ & $\begin{array}{l}\text { Drainage } \\
\text { time } \\
\text { (days) }\end{array}$ & $\begin{array}{c}\text { Urethral } \\
\text { catheter time } \\
\text { (days) }\end{array}$ & $\begin{array}{l}\text { Follow- } \\
\text { up time } \\
\text { (months) }\end{array}$ & Recurrence \\
\hline 52 & $\begin{array}{c}\text { Not } \\
\text { complex }\end{array}$ & 1 & 120 & 80 & 150 & Omentum & 1 & No & 0 & 7 & 14 & 21 & No \\
\hline 47 & Complex & 1.5 & 100 & 60 & 150 & Omentum & 2 & No & 0 & 0 & 14 & 17 & No \\
\hline 41 & Complex & 0.3 & 150 & 100 & 150 & Omentum & 3 & Yes & 5 & 10 & 25 & 18 & No \\
\hline 47 & Complex & 2 & 100 & 70 & 50 & Omentum & 1 & Yes & 5 & 0 & 10 & 1 & No \\
\hline
\end{tabular}

\section{DISCUSSION}

Vesicovaginal fistulae are rare, but when they are present, they are devastating for women, causing distress due to persistent leakage of urine. Most vesicovaginal fistulae are the result of pelvic surgeries, wherein 90\% occur after hysterectomy $(1-3,4,6)$.

When VVFs are large or do not respond to conservative measures, surgical correction is indicated $(5,6)$. Surgical approaches are either vaginal or abdominal $(3,5)$. The selected approach to repair VVF depends on several factors, such as the size, number and location of fistulae, history of repair and concomitant pathological conditions. Although the morbidity of open abdominal repair is significant compared with that of the transvaginal approach, abdominal surgery is usually preferred in patients with a large $(>3 \mathrm{~cm}$ ) or supratrigonal fistula, a fistula in close proximity to ureteric surgical trauma, allowing for more rapid convalescence $(8,10-16)$. Sotelo et al. (8) reported an approach in which the bladder is first intentionally opened, accurately leading to the fistulous tract without requiring additional vaginal incisions or further dissection of the vesicovaginal space. Thus, laparoscopy enables a limited cystostomy that improves upon the historically morbid 0'Connor procedure, in which the bladder is bi-valved to the level of the fistula (12). Using the technological advantages of robotic technology (EndoWrist $^{\mathrm{TM}}$ instruments with increased degrees of freedom leading to improved dexterity and absence of fatigue, three-dimensional [3-D] vision with improved depth perception, motion scaling, tremor filtration, higher magnification, and the surgeon's ergonomic position in a longstanding and time-consuming operation), it is possible to perform laparoscopic repair of VVF with robotic 
assistance, respecting the basic surgical principles of fistula reconstruction (17).

In 2005, Melamud et al. (18) reported the first use of the robotic system for VVF repair. In the initial stages, they used standard laparoscopic instruments until the fistula was reached. Then, they completed the surgery robotically. After this initial work, additional studies performed a similar transabdominal transvesical approach with excellent results (17-25). Our results are comparable to other studies in terms of efficacy and lack of recurrence. The operation time in robot assisted laparoscopic cases ranges from 110 to 330 minutes $(18,20-24)$; and the mean time was 117.5 minutes. The mean estimated blood loss in our series was $100 \mathrm{~mL}$, which is within the range of minimal to $150 \mathrm{~mL}$ reported in other studies $(18,20-24)$.

In this paper, we report a series of four cases undergoing a VVF repair using the robotic transabdominal-transvaginal approach, which minimizes bladder incision and may potentially reduce the recurrence rate and irritative voiding symptoms. Due to the fistulae characteristics, we preferred the transabdominal approach. When using the transvaginal approach, the vagina is first incised and the fistula tract is identified without performing a cystostomy, which is the main difference with previous robotic work (18-24). This approach is specifically useful in complex cases in patients with a history of prior surgeries whose vesicovaginal space is difficult to dissect. The limitation of our study lies in the small sample size and the lack of comparison with other techniques. We do not show evidence of a minimal incision in the vagina produce less frequent irritative symptoms than the incision in the bladder.

\section{CONCLUSIONS}

We present a novel transabdominal transvaginal robotic approach to manage VVF, which minimizes bladder incision and with low morbidity. Our approach is an attractive alternative for managing complex VVF. Robot assisted surgery offers the benefits of minimally invasive laparoscopy while providing the surgeon with enhanced vision and endowrist movements comparable to open surgery. Additional studies with a large number of patients and comparing this technique to other approaches are required to validate this novel approach.

\section{CONFLICT OF INTEREST}

None declared.

\section{REFERENCES}

1. Kochakarn W, Pummangura W. A new dimension in vesicovaginal fistula management: an 8-year experience at Ramathibodi hospital. Asian J Surg. 2007;30:267-71.

2. Bai SW, Huh EH, Jung da J, Park JH, Rha KH, Kim SK, et al. Urinary tract injuries during pelvic surgery: incidence rates and predisposing factors. Int Urogynecol J Pelvic Floor Dysfunct. 2006;17:360-4.

3. Romics I, Kelemen Z, Fazakas Z. The diagnosis and management of vesicovaginal fistulae. BJU Int. 2002;89:7646.

4. Blaivas JG, Heritz DM, Romanzi LJ. Early versus late repair of vesicovaginal fistulas: vaginal and abdominal approaches. J Urol. 1995 Apr;153(4):1110-2; discussion 1112-3.

5. Eilber KS, Kavaler E, Rodríguez LV, Rosenblum N, Raz S. Ten-year experience with transvaginal vesicovaginal fistula repair using tissue interposition. J Urol. 2003;169:1033-6.

6. Dupont MC, Raz S. Vaginal approach to vesicovaginal fistula repair. Urology. 1996;48:7-9.

7. Judd JP, Siddiqui NY, Barnett JC, Visco AG, Havrilesky LJ, Wu JM. Cost-minimization analysis of robotic-assisted, laparoscopic, and abdominal sacrocolpopexy. J Minim Invasive Gynecol. 2010;17:493-9.

8. Sotelo R, Mariano MB, García-Segui A, Dubois R, Spaliviero M, Keklikian W, Novoa J, Yaime H, Finelli A. Laparoscopic repair of vesicovaginal fistula. J Urol. 2005;173:1615-8.

9. Leng WW, Amundsen CL, McGuire EJ. Management of female genitourinary fistulas: transvesical or transvaginal approach? J Urol. 1998;160(6 Pt 1):1995-9.

10. Das Mahapatra P, Bhattacharyya P. Laparoscopic intraperitoneal repair of high-up urinary bladder fistula: a review of 12 cases. Int Urogynecol J Pelvic Floor Dysfunct. 2007;18:635-9.

11. Nagraj HK, Kishore TA, Nagalaksmi S. Early laparoscopic repair for supratrigonal vesicovaginal fistula. Int Urogynecol J Pelvic Floor Dysfunct. 2007;18:759-62.

12. Shah SJ. Laparoscopic transabdominal transvesical vesicovaginal fistula repair. J Endourol. 2009;23:1135-7.

13. Abdel-Karim AM, Mousa A, Hasouna M, Elsalmy S. Laparoscopic transperitoneal extravesical repair of vesicovaginal fistula. Int Urogynecol J. 2011;22:693-7. 
14. Zhang Q, Ye Z, Liu F, QiX, Shao C, He X, Zhang D. Laparoscopic transabdominal transvesical repair of supratrigonal vesicovaginal fistula. Int Urogynecol J. 2013;24:337-42.

15. Miklos JR, Sobolewski C, Lucente V. Laparoscopic management of recurrent vesicovaginal fistula. Int Urogynecol J Pelvic Floor Dysfunct. 1999;10:116-7.

16. Wong C, Lam PN, Lucente VR. Laparoscopic transabdominal transvesical vesicovaginal fistula repair. J Endourol. 2006;20:240-3; discussion 243.

17. Sotelo R, Moros V, Clavijo R, Poulakis V. Robotic repair of vesicovaginal fistula (VVF). BJU Int. 2012 May;109(9):1416-34

18. Melamud O, Eichel L, Turbow B, Shanberg A. Laparoscopic vesicovaginal fistula repair with robotic reconstruction. Urology. 2005;65:163-6.

19. Paparel P, Caillot JL, Perrin P, Ruffion A. Surgical principles of omentoplasty in urology. BJU Int. 2007;99:1191-6.

20. Sundaram BM, Kalidasan G, Hemal AK. Robotic repair of vesicovaginal fistula: case series of five patients. Urology. 2006;67:970-3.

21. Hemal AK, Kolla SB, Wadhwa P. Robotic reconstruction for recurrent supratrigonal vesicovaginal fistulas. J Urol. 2008;180:981-5.
22. Schimpf MO, Morgenstern JH, Tulikangas PK, Wagner JR. Vesicovaginal fistula repair without intentional cystotomy using the laparoscopic robotic approach: a case report. JSLS. 2007;11:378-80.

23. Kurz M, Horstmann M, John H. Robot-assisted laparoscopic repair of high vesicovaginal fistulae with peritoneal flap inlay. Eur Urol. 2012;61:229-30.

24. Rogers AE, Thiel DD, Brisson TE, Petrou SP. Robotic assisted laparoscopic repair of vesico-vaginal fistula: the extravesical approach. Can J Urol. 2012;19:6474-6.

25. Tenggardjaja CF, Goldman HB. Advances in minimally invasive repair of vesicovaginal fistulas. Curr Urol Rep. 2013;14:253-61.

Correspondence address:

Luciano Nunez Bragayrac, MD Instituto Medico La Floresta Avenida Santa Ana, Anexo B, Piso 2

Urb. La Floresta, Caracas, Venezuela E-mail: nunez@urologialaparoscopica.net 